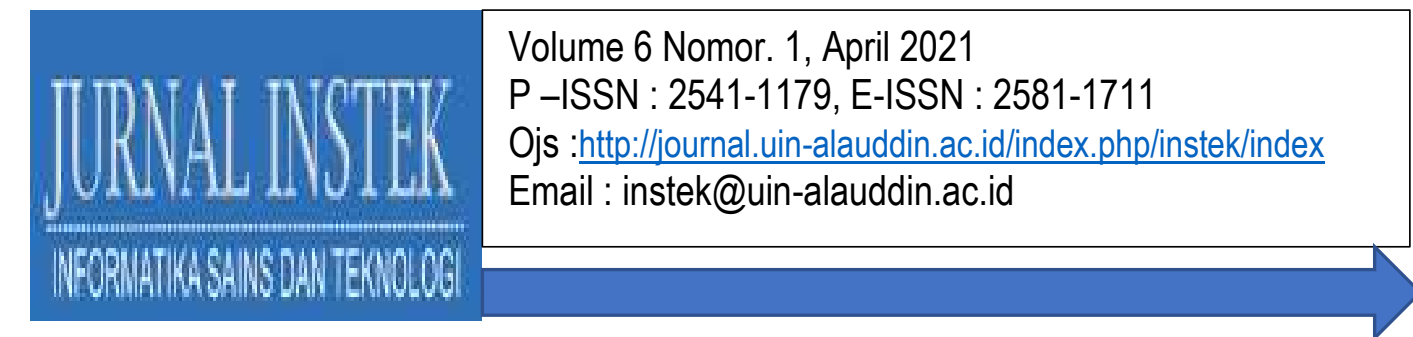

\title{
PENERAPAN METODE CREATIVE LEARNING CYCLE PADA PEMBELAJARAN PEMROGRMAN BAGI SISWA SMP
}

\author{
DIAN ANGGRAINI ${ }^{1}$, ASYIFA IMANDA SEPTIANA ${ }^{2}$, INDIRA \\ SYAWANODYA ${ }^{3}$
}

Prodi Rekayasa Perangkat Lunak, Universitas Pendidikan Indonesia ${ }^{123}$

Email: dian.anggraini@upi.edu ${ }^{1}$, asyifa@upi.edu²,indira@upi.edu ${ }^{3}$

\begin{abstract}
ABSTRAK
Pelajaran pemrograman semestinya sudah diajarkan sejak dini. Untuk dapat mengajarkan pemrograman kepada siswa dibutuhkan usaha yang besar agar dapat diterima dan membuat siswa tertarik untuk mempelajari pemrograman. Pada penelitian ini, kami menyajikan model pembelajaran creative learning cycle untuk mendukung siswa dalam pembelajaran pemrograman. Model Creative Learning Cycle memiliki lima tahapan yang meliputi imagine, create, play, share, dan reflect, masing masing tahapan dapat membantu siswa dalam mengembangkan ide pemikiran yang kreatif dalam pemecahan masalah dan mampu memberikan solusi dari permasalahan tersebut sehingga dapat meningkatkan minat siswa dalam pembelajaran pemrograman. Berdasarkan hasil analisis diperoleh bahwa $76 \%$ siswa menyukai pembelajaran pemrograman, $71 \%$ siswa berpikir pemrograman mudah dimengerti dan $74 \%$ siswa bahkan ingin belajar pemrograman lebih lanjut.
\end{abstract}

Kata Kunci: Creative Learning Cycle, Metode Pembelajaran, Pemrograman

\section{PENDAHULUAN}

Pada era revolusi industrial 4.0, diberbagai sektor bidang telah menggunakan digitalisasi. Revolusi industrial 4.0 mempunyai ciri teknologi yang menyatu dengan masyarakat dan tubuh manusia, robotik, quantum komputasi, augmented reality, bioteknologi, 3D printing, otomasi kendaraan, internet, sistem virtual dan fisik bekerjasama secara global (Triyono,M.B, 2017). Revolusi industri 4.0 menuntut sumber daya manusia untuk berpikir kritis, memiliki komunikasi yang baik, mampu berkolaborasi, mampu bersaing dan mempunyai kreativitas. Apabila tidak mampu beradaptasi dengan perkembangan teknologi yang cepat maka tidak akan mampu bersaing dalam era digitalisasi.

Pembelajaran pemograman merupakan salah satu cara agar dapat bersaing di era digitalisasi. Pemahaman tentang pemograman dan cara pembuatan program telah menjadi kemampuan yang semakin penting untuk dapat beradaptasi pada era digital. Pemograman sama pentingnya dengan keterampilan dasar lainnya yang 


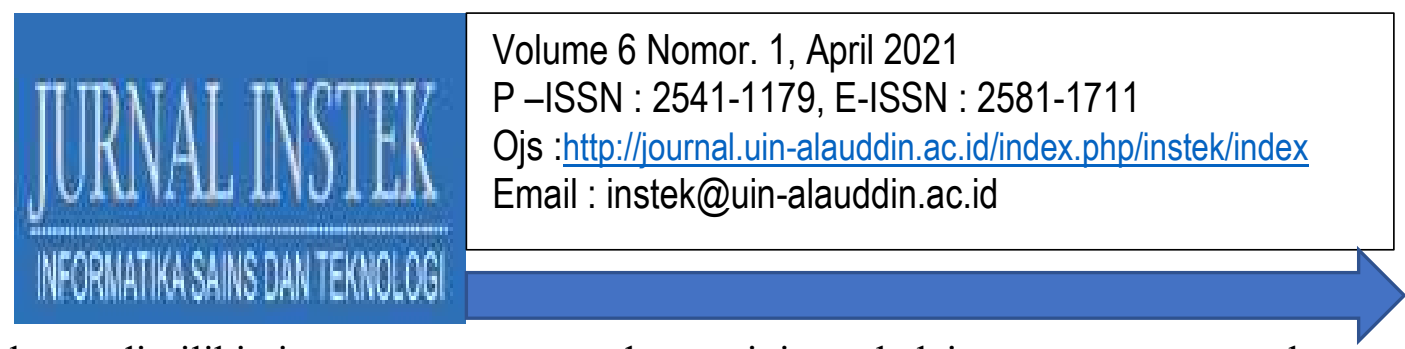

harus dimiliki siapa pun, namun pada saat ini pembelajaran pemrograman hanya diberikan kepada siswa SMA ataupun mahasiswa. Pelajaran pemrograman semestinya sudah diajarkan kepada anak anak dan remaja awal. Pemrograman dapat mengembangkan cara berfikir terstruktur, logis dan kreatif, membuat anak belajar untuk membangun, memperbaiki dan merefleksikan ide ide mereka. Untuk dapat mengajarkan pemrograman kepada siswa dibutuhkan usaha yang besar agar dapat diterima dan membuat siswa tertarik untuk mempelajari pemrograman.

Berdasarkan uraian diatas menunjukan bahwa perlunya model pembelajaran yang memberikan kemudahan dan ketertarikan kepada siswa untuk dapat mempelajari pemrograman. Pada metode pembelajaran ini menuntut siswa untuk berpartisipasi aktif secara langsung dalam proses pembelajaran dan memberikan tanggung jawab kepada siswa. Siswa diminta untuk mampu bekerjasama dalam tim dan dapat saling betukar pikiran tentang pengetahuan yang mereka dapatkan dengan teman dan guru, sehingga menimbulkan anggapan bahwa pemrograman itu mudah dan menarik. Model creative learning cycle dipredikasi mampu membantu mahasiswa dalam pembelajaran pemrograman.

\section{METODE PENELITIAN}

Penelitian akan dilakukan selama tiga bulan kepada siswa SMP. Metode penelitian digunakan untuk perancangan penelitian yang akan dilakukan. Metode yang digunakan dalam penelitian ini adalah metode tindakan (action research). Metode tindakan menggunakan metode pengumpulan data yang dapat dilakukan secara kualitatif dan kuantitatif, tetapi selalu diarahkan pada spesifik dan praktis, dan berusaha mencari solusi terhadap permasalahan yang dihadapi (Yaumi, M dan Damopolii, M, 2016).

Tahap - tahap penelitian yang akan dilaksanakan dibagi menjadi 4(empat) bagian yaitu tahap perencanaan, mengambil tindakan, evaluasi dan tahap penyajian data hasil penelitian. Data yang sudah dikumpulkan selanjutnya akan diolah untuk mengetahui pengaruh Creative Learning Cycle terhadap pembelajaran pemrograman. 


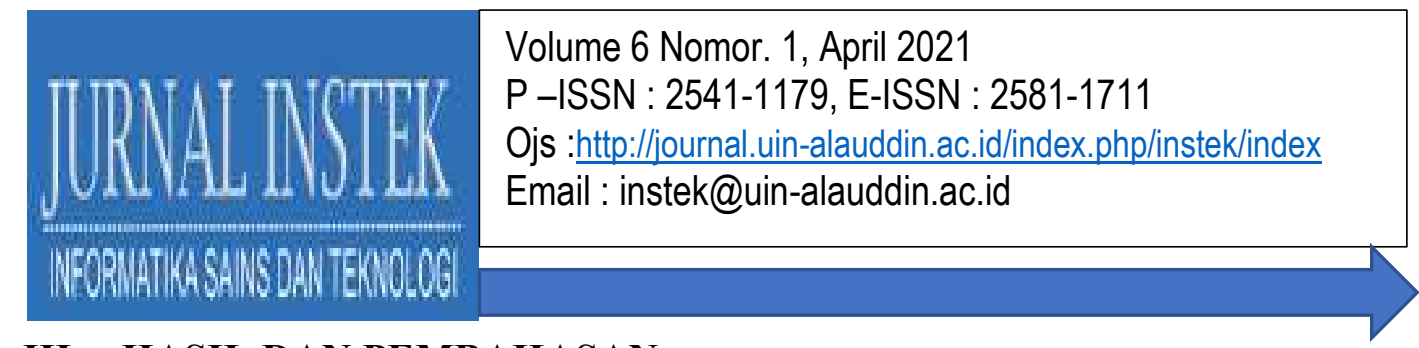

\section{HASIL DAN PEMBAHASAN}

Pembelajaran pemograman merupakan pelajaran yang belum banyak diketahui oleh siswa, namun sebagian siswa sudah mulai mempelajari pemrograman dengan cara otodidak dimana mereka mengikuti tutorial yang ada tanpa mengetahui masalah dan penyelesaian yang sebenarnya. Tidak jarang sebagian siswa yang baru memulai untuk mempelajari pemrograman memiliki kesulitan untuk dapat memahami pemrograman dan biasanya mereka akan berhenti untuk mempelajarinya karna dianggap sulit dan tidak menarik. Tantangan dalam penelitian ini adalah model pembelajaran yang mampu menarik minat siswa dalam pembelajaran pemrograman sehingga pemograman mudah untuk dipahami. Metode creative learning diprediksi mampu membantu siswa untuk memahami pemrograman. Resnick (Putro, B.L,2013) mengemukakan bahwa salah satu pengembangan metode pembelajaran Learning by Doing adalah metode creative learning dengan tujuan membantu siswa belajar merancang, membuat, dan menciptakan sesuatu. Creative learning cycle mempunyai tahapan yang dimulai dari Imagine, Create, Play, Share, Reflect lalu kembali lagi ke Imagine.

Pada penelitian ini siswa mempelajari pemrograman Scratch dimana siswa dituntun untuk bisa membuat game sederhana yang dikerjaan secara berkelompok. Pada tahap imagine siswa diminta untuk mengemukan ide dengan cara membayangkan suatu kasus yang dapat membantu dalam proses pemecahan masalah dalam bentuk storyboard. Tahap create merupakan tahap dimana siswa menciptakan game sederhana dengan menggunakan Scratch sesuai dengan ide ide mereka secara berkelompok, ini bertujuan untuk mengajarkan kepada siswa agar dapat bekerja sama dalam tim dan memiliki tanggung jawab. Hernandez dan Resnick, M. mengemukakan bahwa "Kemampuan untuk membuat (bukan hanya berinterkasi) suatu konten merupakan kunci dari pencapaian kesadaran digital dan menjadi partisipan penuh dalam dunia online yang interaktif" (Arifin, Willdan Aprizal, 2016). Selanjutnya ke tahap play yang bukan bearti bermain, namun siswa belajar melalui eksperimen. Siswa melakukan pengujian terhadap game yang dibuat dan berusaha memperbaiki kekurangan dari hasil pengujian. Pada tahap share siswa 


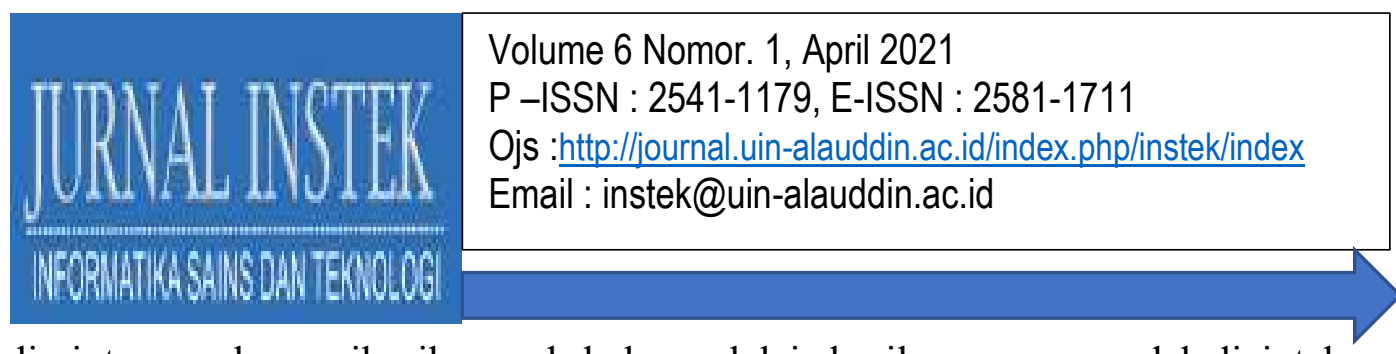

diminta mengkomunikasikan pada kelompok lain hasil game yang sudah diciptakan melalui pemaparan didepan kelas, tahap ini bertujuan agar siswa dapat berbagi ide satu sama lain. Tahap selanjutnya siswa melakukan refleksi agar dapat membuat karya yang lebih baik dan luas dari sebelumnya.

Untuk mengetahui pengaruh metode creative learning cycle terhadap pembelajaran pemrograman bagi siswa diberikan kuisioner yang berisi penilaian terhadap minat siswa dalam pemrograman, kemampuan siswa dalam pemograman dan ketertarikan siswa untuk mempelajari pemrograman lebih lanjut. Berikut hasil kuisioner dalam bentuk persentase dan dinilai berdasarkan skala likert. Skala likert memiliki lima bobot penilaian yaitu sangat setuju (SS), setuju (S), netral (N), tidak setuju (TS) dan sangat tidak setuju (STS).

Table 1 Hasil Analisis Kuisioner

\begin{tabular}{|l|c|c|c|c|c|}
\hline & SS & S & N & TS & STS \\
\hline $\begin{array}{l}\text { Minat siswa dalam } \\
\text { pemrograman }\end{array}$ & 10 & 26 & 0 & 7 & 2 \\
\hline $\begin{array}{l}\text { Kemampuan siswa dalam } \\
\text { pemograman }\end{array}$ & 13 & 15 & 3 & 11 & 3 \\
\hline $\begin{array}{l}\text { Ketertarikan siswa untuk } \\
\text { mempelajari pemrograman } \\
\text { lebih lanjut }\end{array}$ & 6 & 30 & 0 & 7 & 2 \\
\hline
\end{tabular}

Berdasarkan hasil analisis kuisioner yang diberikan kepada 45 siswa sebagai responden dalam penelitian, maka diperoleh bahwa 76\% siswa minat dan menyukai pembelajaran pemrograman, $71 \%$ siswa berpikir pemrograman mudah dimengerti dan mengakui kemampuan pemrograman siswa meningkat setelah mempelajari pemrograman dengan metode creative learning dan $74 \%$ siswa bahkan ingin belajar pemrograman lebih lanjut.

\section{KESIMPULAN}

Penelitian ini telah mempresentasikan metode pembelajaran creative learning untuk mendukung siswa dalam pembelajaran pemrograman. Metode creative learing dapat 


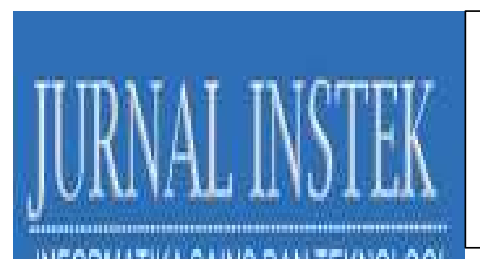

Volume 6 Nomor. 1, April 2021

P-ISSN : 2541-1179, E-ISSN : 2581-1711

Ojs :http://journal.uin-alauddin.ac.id/index.php/instek/index

Email : instek@uin-alauddin.ac.id

diimplementasikan untuk meningkatkan kemampuan siswa dalam pembelajaran pemrograman dan dapat menarik minat siswa dalam pembelajaran pemrograman. Berdasarkan hasil analisis yang telah dilakukan diperoleh bahwa $76 \%$ siswa menyukai pembelajaran pemrograman, $71 \%$ siswa berpikir pemrograman mudah dimengerti dan $74 \%$ siswa bahkan ingin belajar pemrograman lebih lanjut.

\section{DAFTAR PUSTAKA}

Triyono, M.B. 2017. Tantangan Revolusi Industri Ke 4 (I4.0) Bagi Pendidikan Vokasi. Prosiding Seminar Nasional Vokasi dan Teknologi (SEMNASVOKTEK). 28 Oktober 2017. Denpasar: Fakultas Teknik dan Kejuruan, Universitas Pendidikan Ganesha. ISSN Cetak: 2541-2361 | ISSN Online: 2541-3058. hal 12-16.

Yaumi, M dan Damopolii, M .2016. Action Research: Teori, Model \& Aplikasi. Jakarta: Kencana Prenadamedia Group. Hal 4.

Putro, B. L.2013. Development Of Learning By Designing For Supporting The Learning Process In Class And Its Effect On Learning Effectiveness In Computer Science Students Upi Academic Year 2012/2013. International Seminar on Mathematics, Science, and Computer Science Education. 13 Oktober 2013. Bandung: Faculty of Mathematics and Science Education. ISBN 978-602-95549-2-2. Hal 62.

Arifin, Willdan Aprizal.2016. Pengaruh Tahapan Imagine Pada Metode Creative Learning Cycle Terhadap Keterampilan Abad-21 Menggunakan Sistem Manajemen Pembelajaran Studi Kasus: Mata Pelajaran Pemrograman Dasar Kelas X Teknik Komputer dan Jaringan SMK PU N Bandung. S1 thesis, Universitas Pendidikan Indonesia.

Resnick, M.2007. All I really need to know (about creative thinking) I learned (by studying how children learn) in kindergarten. Proceedings of the 6th ACM SIGCHI conference on Creativity \& cognition (pp. 1-6). ACM.

Brennan, K., Resnick, M., \& Hernandez, A. 2010. Making projects, making friends: Online community as catalyst for interactive media creation. New Directions for Youth Development (128), 75-83 